\title{
CARACTERÍSTICAS RADIOLÓgICAS DE LOS HEMANGIOENDOTELIOMAS EPITELIOIDES DE PARTES BLANDAS, HÍGADO Y HUESO
}

\author{
Drs. Juan Jesús Gómez $H^{(1)}$, María de los Santos Gallego $G^{(2)}$, Paula Orenes $C^{(1)}$, Ana Belén Enguita $V^{(3)}$. \\ 1. Médico Especialista en Radiología, Hospital Universitario 12 de Octubre, Madrid, España. \\ 2. Médico Especialista en Radiología y Doctora en Medicina, Hospital Universitario 12 de Octubre, Madrid, España. \\ 3. Médico Especialista en Anatomía Patológica, Hospital Universitario 12 de Octubre, Madrid, España.
}

\section{RADIOLOGIC FEATURES OF EPITHELIOID HEMANGIOEN- DOTHELIOMA OF SOFT TISSUES, LIVER AND BONE}

\begin{abstract}
Objective: To contribute to the awareness of imaging features of epithelioid hemangioendothelioma $(E H E)$ in soft tissues, liver and bone. Radiographic images were obtained from patients with histological diagnosis of EHE treated in our institution over the past twenty years. We reviewed the Computed Tomography, MRI, and ultrasound findings concerning size, number, behavior with and without intravenous contrast agent, signs of local involvement, and distant metastases. Imaging findings were correlated with histological results and clinical evolution was analyzed. Findings: Soft tissue EHE appeared as solid masses without specific features. Liver EHE showed a characteristic peripheral location and progressive enhancement. Osseous EHE behaved as lytic lesions with soft tissue mass or adjacent edema. Two liver EHE and one epithelioid hemangioendothelioma of bone were initially diagnosed as metastasis. Conclusion: The epithelioid hemangioendothelioma may pose problems in differential diagnosis; therefore, having awareness of its radiological features enables us to determine proper diagnosis and treatment.

Keywords: Computed tomography, Epithelioid hemangioendothelioma, MRI, Ultrasound.
\end{abstract}

Resumen: Objetivo: Contribuir al conocimiento de las características radiológicas de los hemangioendoteliomas epitelioides (HEE) en partes blandas, hígado y hueso.

Gómez $\boldsymbol{J}$ y cols. Características radiológicas de los hemangioendoteliomas epitelioides de partes blandas, hígado y hueso. Rev Chil Radiol 2010; 16(3): 147-153.

Correspondencia: Dr. Juan Jesús Gómez H.

Servicio de Radiodiagnóstico del Hospital Universitario 12 de Octubre, Av. Córdoba s/n, 28041, Madrid, España.

Email: juanje81@hotmail.com

Trabajo recibido el 22 de abril de 2010, aceptado para publicación el 19 de agosto de 2010.
Se obtuvieron las imágenes radiológicas de los pacientes con diagnóstico histológico de HEE en nuestra institución en los últimos veintitrés años. Revisamos los hallazgos en tomografía computarizada, resonancia magnética y ecografía: tamaño, número, comportamiento con y sin contraste intravenoso, signos de afectación local y a distancia. Correlacionamos los hallazgos de imágenes con los histológicos y revisamos la evolución clínica. Hallazgos: Los HEE de partes blandas aparecieron como masas sólidas sin hallazgos específicos. Los HEE hepáticos mostraron una localización característica periférica y con realce progresivo. Los HEE óseos aparecieron como lesiones líticas con masa de partes blandas adyacentes o edema. Dos HEE hepáticos y uno óseo fueron interpretados inicialmente como metástasis. Conclusión: EI HEE puede crear problemas de diagnóstico diferencial, por lo que conociendo sus características radiológicas es posible sugerir el diagnóstico y tratamiento adecuados.

Palabras clave: Ecografía, Hemengioendotelioma epitelioide, Resonancia magnética, Tomografía computarizada.

\section{Introducción}

El hemangioendotelioma epitelioide (HEE) es un tumor vascular poco frecuente, de malignidad intermedia entre el hemangioma epitelioide y el angiosarcoma epitelioide, con una mortalidad estimada de $20 \%{ }^{(1,2)}$. Aunque su frecuencia de presentación es baja, puede originar problemas en el diagnóstico diferencial con otros tumores primarios o metastásicos, por lo que consideramos interesante revisar nuestra experiencia y aportar elementos útiles en el diagnóstico de los HEE en las tres localizaciones más frecuentes, con el propósito de proporcionar información de utilidad para el diagnóstico de estos tumores mediante el uso de las técnicas de imagen cotidianas: radiografías simples, ultrasonografía (US), tomografía computarizada (TC) y resonancia magnética $(\mathrm{RM})$. 


\section{Material y métodos}

Se revisó la base de datos del Departamento de Anatomía Patológica de nuestro hospital en busca de los HEE con diagnóstico histológico desde el 1 de julio de 1986 hasta el 1 de julio de 2009. Se establecieron como criterios principales de inclusión en el estudio la existencia de confirmación anatomopatológica de HEE y la existencia de exámenes de imágenes obtenidos en nuestra institución antes del diagnóstico histológico. Se identificaron un total de 25 pacientes con HEE de diferentes localizaciones, que cumplían los criterios de inclusión. El Departamento de Anatomía Patológica revisó las muestras histológicas y se excluyeron 8 pacientes cuyas muestras no cumplían los criterios actuales de $\mathrm{HEE}^{(3)}$, quedando un total de 17 casos. De ellos, 5 fueron HEE de partes blandas, 5 hepáticos, 3 óseos, 3 de piel y 1 pulmonar. Posteriormente se excluyeron 7 pacientes: 3 con HEE cutáneos (por no requerir técnicas de imagen para el diagnóstico) y los otros 4 por no tener imágenes radiológicas antes del diagnóstico histológico (un HEE de partes blandas, dos hepáticos y uno pulmonar). Se evaluaron finalmente 10 pacientes.

Las muestras para diagnóstico histológico de los pacientes con HEE correspondieron a biopsias en 5 casos ( 2 de tejidos blandos, 1 hepático y 2 óseo) y en los 5 restantes a resecciones quirúrgicas del tumor (2 de tejidos blandos, 2 hepáticos y 1 óseo). Revisamos su comportamiento en las diferentes técnicas de imagen, especialmente en US, TC y RM, teniendo en cuenta el tamaño y número de lesiones, su comportamiento con y sin contraste intravenoso, signos de invasión local y metástasis a distancia. También se evaluaron las radiografías simples en los HEE de hueso, así como una mielografía en un HEE vertebral. Analizamos la evolución clínica de estos pacientes y la respuesta a los tratamientos recibidos.

\section{Resultados}

Todos los pacientes con HEE de tejidos blandos y óseos fueron hombres $(n=7)$ y los pacientes con HEE hepáticos fueron mujeres $(n=3)$. La edad de los pacientes varió entre 26 y 51 años de edad, con un promedio de 37 años de edad: media de 36 años en los HEE de tejidos blandos y óseos y de 30 años en los hepáticos. El 27\% de nuestros pacientes desarrolló metástasis (50\% de los HEE de tejidos blandos y $33 \%$ de los hepáticos).

Los estudios de imágenes disponibles para cada tipo de tumor revisado se resumen en la Tabla I.

- Localización en partes blandas: Se presentaron como tumores locales con dolor asociado en todos los pacientes, localizados en: muslo (músculo sartorio), rodilla (región poplítea), espalda (tejido subcutáneo) y unión cervicotorácica. Tanto en US como en TC (Figura 1), los HEE aparecieron como una masa sólida homogénea o discretamente heterogénea; en el paciente con el tumor de la unión cervicotorácica la TC realizada con contraste intravenoso, la masa evidenció realce periférico (Figura 1b).

\begin{tabular}{|c|c|c|c|c|}
\hline tocatización & Rx-simple- & US & $\mp \mathrm{C}$ & $\mathrm{RM}$ \\
\hline $\begin{array}{l}\text { Partes blandas } \\
(n=4)\end{array}$ & & 2 & 1 & 3 \\
\hline $\begin{array}{l}\text { Hueso } \\
(n=3)\end{array}$ & 2 & & 2 & 1 \\
\hline $\begin{array}{l}\text { Hígado } \\
(\mathrm{n}=3)\end{array}$ & & 1 & 3 & 1 \\
\hline
\end{tabular}
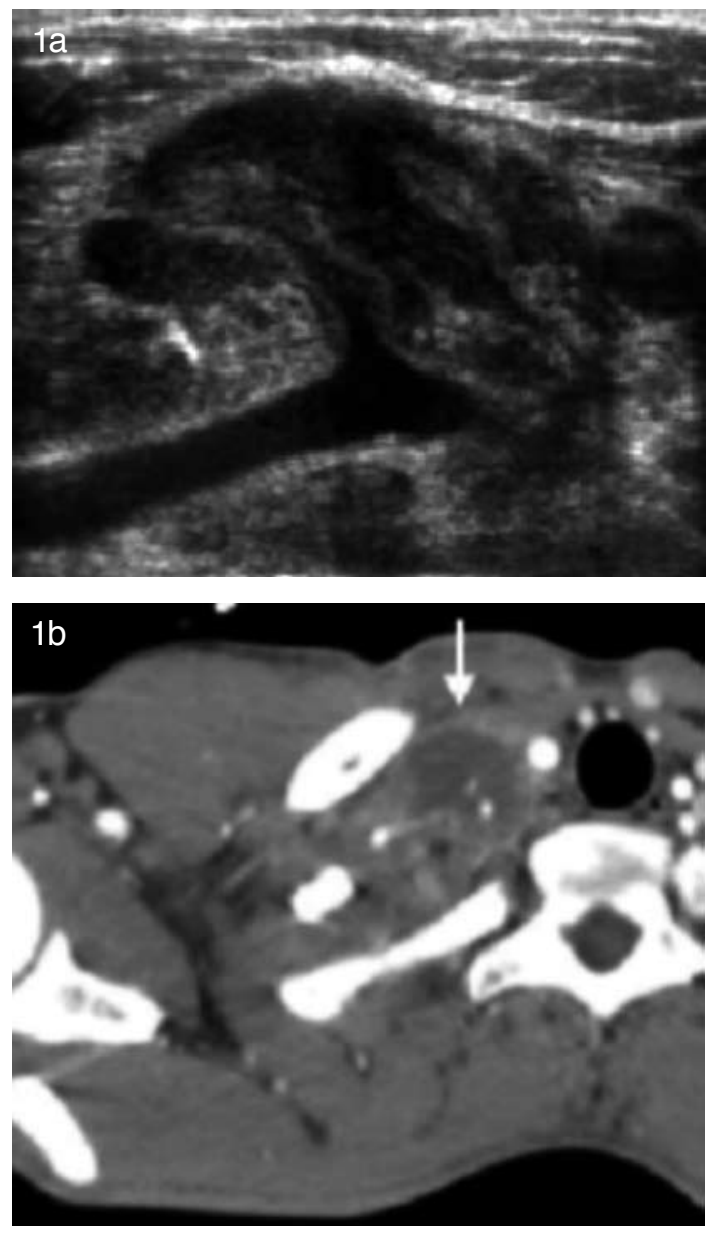

Figura 1. a) Varón de 27 años. Dolor y tumoración cervical. US muestra una masaheterogénea sólida ovalada que rodea el origen de la arteria subclavia y las arterias vertebrales. b) TC con contraste intravenoso muestra una masa homogénea hipodensa con realce periférico (flecha). 
En RM las masas mostraron señal hipointensa homogénea en las imágenes potenciadas en T1 (Figura 2a) y señal hiperintensa homogénea en las secuencias potenciadas en T2 (Figura 2b). Tras la administración de contraste intravenoso (gadolinio), las masas mostraron dos tipos de captación: realce periférico en los HEE de la unión cervicotorácica, muslo y rodilla, y realce heterogéneo en el HEE de la espalda. En las muestras histológicas, este último no presentaba áreas de necrosis significativa ni degeneración quística, mientras que éstas se observaban en el resto de los HEE de partes blandas.
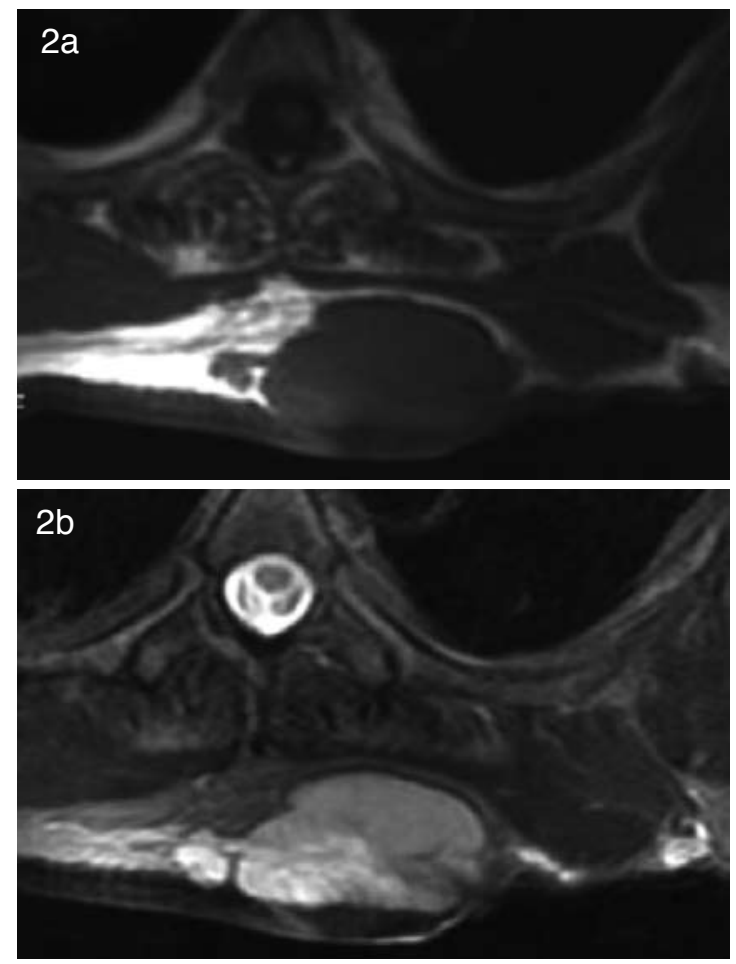

Figura 2. a) Varón de 50 años. Tumoración en la espalda. La $R M$ revela una masa homogénea bien definida, subcutánea, hipointensa en cortes axiales de secuencias potenciadas en T1. b) La masa es hiperintensa en secuencias potenciadas en T2.

Dos pacientes evidenciaban metástasis en el momento del diagnóstico radiológico: el tumor en el muslo en la región preauricular y el de espalda a nivel pulmonar. Se realizó cirugía en los pacientes con HEE de muslo, rodilla y espalda. El paciente con la neoplasia de la unión cervicotorácica recibió únicamente quimioterapia, debido a que el tumor no era resecable. La evolución clínica del paciente con la lesión de la unión cervicotorácica fue rápida, falleciendo el paciente 11 meses después del diagnóstico. El paciente con HEE en el muslo abandonó sus controles 6 meses después del diagnóstico. El paciente con HEE de espalda fue seguido durante 13 años (con varias recurrencias locales y una metástasis en los ganglios linfáticos). El paciente con HEE en el hueco políteo fue seguido durante 8 años, sin recidivas.
- Localización hepática: Las 3 pacientes presentaron dolor abdominal y elevación de enzimas hepáticas; todas ellas mostraban múltiples lesiones hepáticas en los exámenes de imagen, con dos formas de presentación diferentes valorados en TC y RM: la primera $(n=1)$ fue nodular, con lesiones focales sugestivas de metástasis y la segunda $(n=2)$ fue más difusa, con lesiones focales con tendencia a confluir, en su mayor parte de situación periférica.

En US, el tumor no mostró hallazgos específicos, apareciendo como nódulos hipoecoicos bien definidos. En la TC sin contraste intravenoso, los nódulos aparecieron iso o hipodensos respecto al resto del parénquima hepático; tras la administración de contraste intravenoso, los HEE mostraron un realce progresivo centrípeto, más evidente en las fases tardías (Figura 3). En una paciente se detectó retracción capsular asociada a una lesión (Figura 3c).

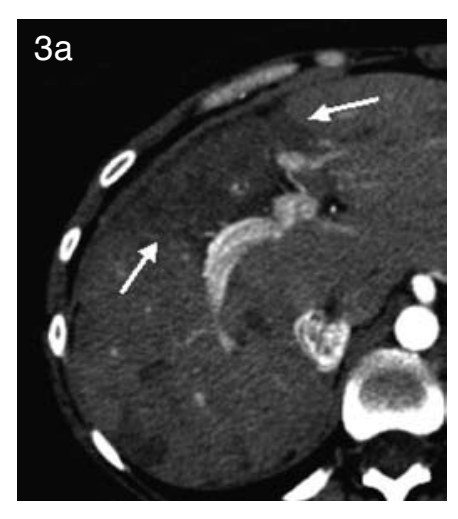

Figura 3. Mujer de 32 años. Dolor abdominal y elevación de enzimas hepáticas. TC con contraste intravenoso: en fase arterial (a), fase venosa (b) y fase tardía (c). El HEE aparece como lesiones focales con tamaño variable (entre 1 y $8 \mathrm{~cm}$ ), de ubicación periférica, confluentes y con realce progresivo centrípeto, más evidente en la fase tardía; las lesiones se asocian a retracción capsular (punta de flecha).
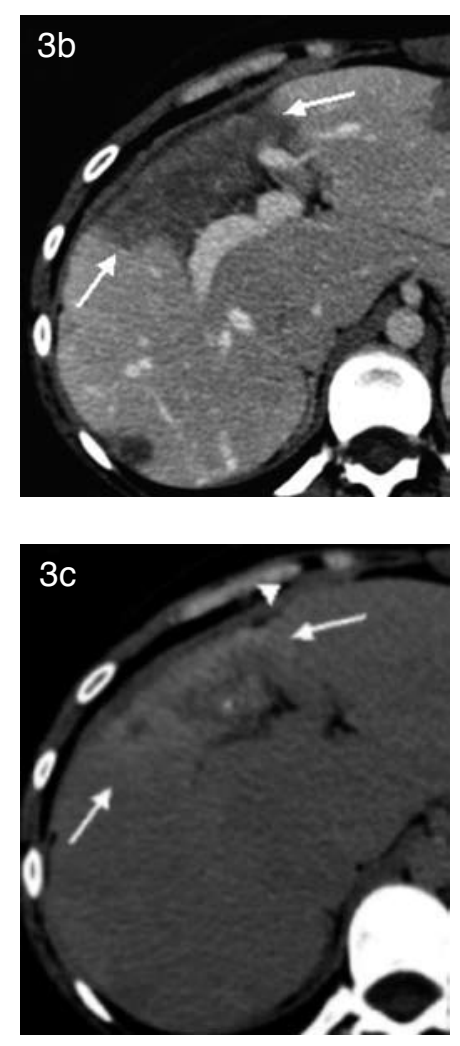
En la RM obtenida en una de las pacientes, las lesiones mostraban hipointensidad homogénea en secuencias potenciadas en T1. En secuencias potenciadas en T2, unas lesiones presentaron hiperintensidad homogénea y otras un aspecto en "diana”, con un núcleo hipointenso y un anillo periférico hiperintenso.

Después de la administración de contraste intravenoso, algunas lesiones mostraron un realce progresivo periférico, adquiriendo también un aspecto en "diana" (Figura 4a, b), más evidente en las fases tardías. En esta última paciente, se administraron también agentes basados en manganeso como contraste intravenoso, permaneciendo los nódulos de HEE con señal hipointensa en secuencias potenciadas en T1, debido a la ausencia de captación (Figura 4c).
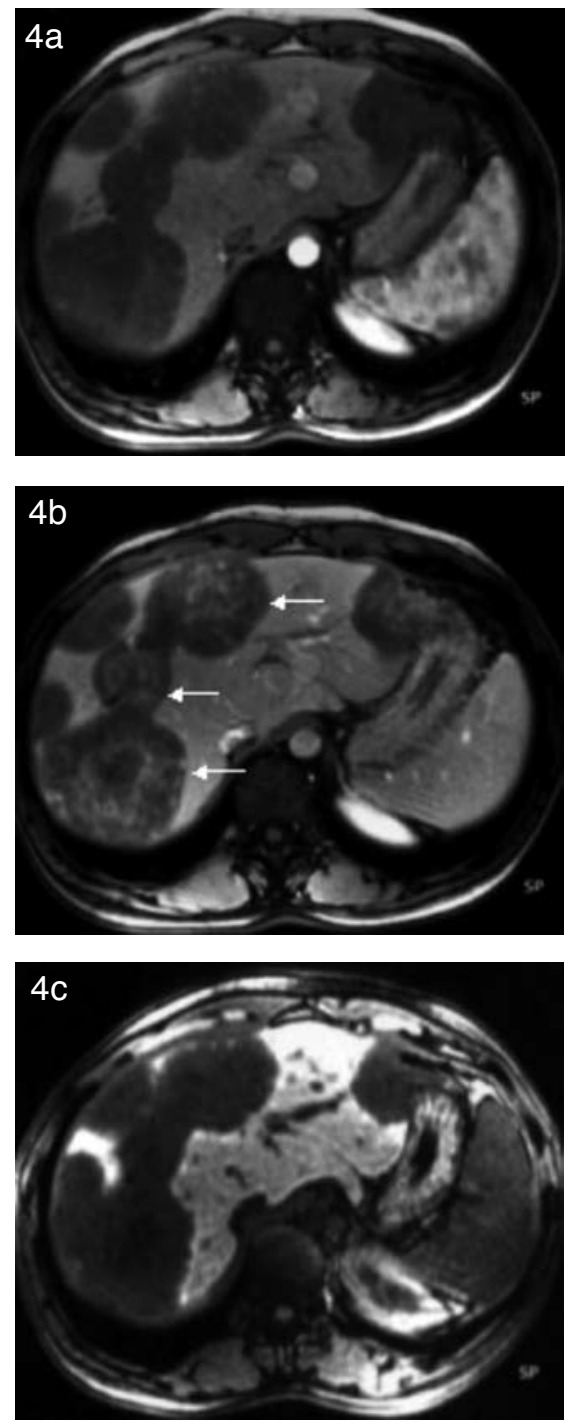

Figura 4. Mujer de 30 años; dolor abdominal y elevación de enzimas hepáticas. Las imágenes coronales de RM con administración de gadolinio, en fase arterial (a) y venosa (b), muestra realce progresivo del HEE, con imágenes en diana (flechas). Secuencias de RM potenciadas T1 tras la administración de mangafodipir trisódico (Mn-DPDP), muestran la ausencia de captación por el HEE (c).
Las lesiones del hígado fueron interpretadas inicialmente como metástasis en 2 pacientes (una paciente tenía un antecedente de leiomiosarcoma tibial, en tratamiento y en remisión) y en una tercera como hemangiomas atípicos. El diagnóstico definitivo de HEE se realizó histológicamente (Figura 5).

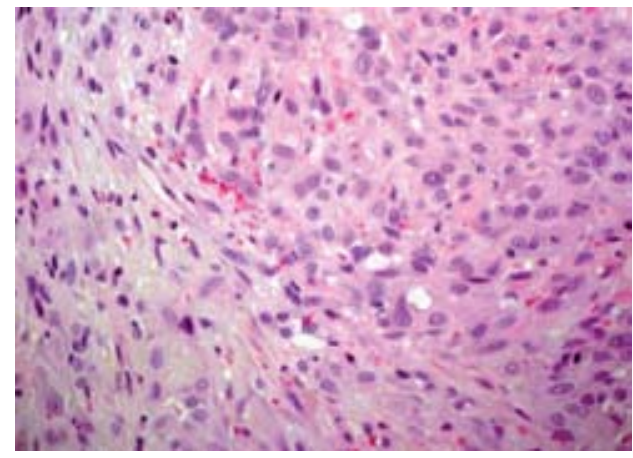

Figura 5. Histología del HEE: tumor de bajo grado con áreas sólidas distribuidas en cordones, compuesto por células endoteliales con características epiteliales. Células con citoplasma eosinófilo y un aspecto epitelioide o histiocítico, se organizan para formar haces perivasculares o nidos.

Dos pacientes fueron tratadas con trasplante de hígado: una ha sido seguida durante siete años sin recidiva y la otra paciente falleció trece años después del diagnóstico debido a metástasis ganglionares del HEE. La tercera paciente fue tratada con quimioterapia durante cinco años, apreciándose progresiva disminución en el tamaño de las lesiones hepáticas.

- Localización ósea: Estos pacientes consultaron por dolor local y los HEE se encontraron a nivel súperoexterno de la órbita, en el calcáneo y en el tercer cuerpo vertebral lumbar. En las radiografías simples de calcáneo y cuerpo vertebral encontramos lesiones líticas agresivas (Figura 6a). La lesión en el calcáneo desarrolló un componente de masa de tejidos blandos y progresó rápidamente afectando a los huesos vecinos (Figura 6b).

Las TC con contraste intravenoso realizada para valoración de los HEE de la órbita y el cuerpo vertebral revelaron lesiones líticas con un borde ligeramente esclerótico (no apreciada en la radiografía simple del cuerpo vertebral) y una masa de partes blandas que mostraba un realce heterogéneo en el tumor de órbita, con realce periférico en el cuerpo vertebral. No había áreas de necrosis o degeneración quística significativas en el análisis histológico de ninguno de estos dos HEE.

Una mielografía mostró la lesión lítica y el compromiso del canal medular producidos por el HEE del cuerpo vertebral (Figura 7). Este paciente tenía un diagnóstico previo de cáncer de próstata, por lo que la lesión inicialmente fue interpretada como una metástasis ósea; la histología del tumor resecado quirúrgicamente planteó el diagnóstico de HEE.

En el paciente con el HEE del cuerpo vertebral, se realizó RM, mostrando una lesión lítica hipointensa en 
T1 e hiperintensa en T2, con discreto borde periférico hiperintenso en T2 sugestivo de edema; se observó realce periférico tras la administración de contraste intravenoso.
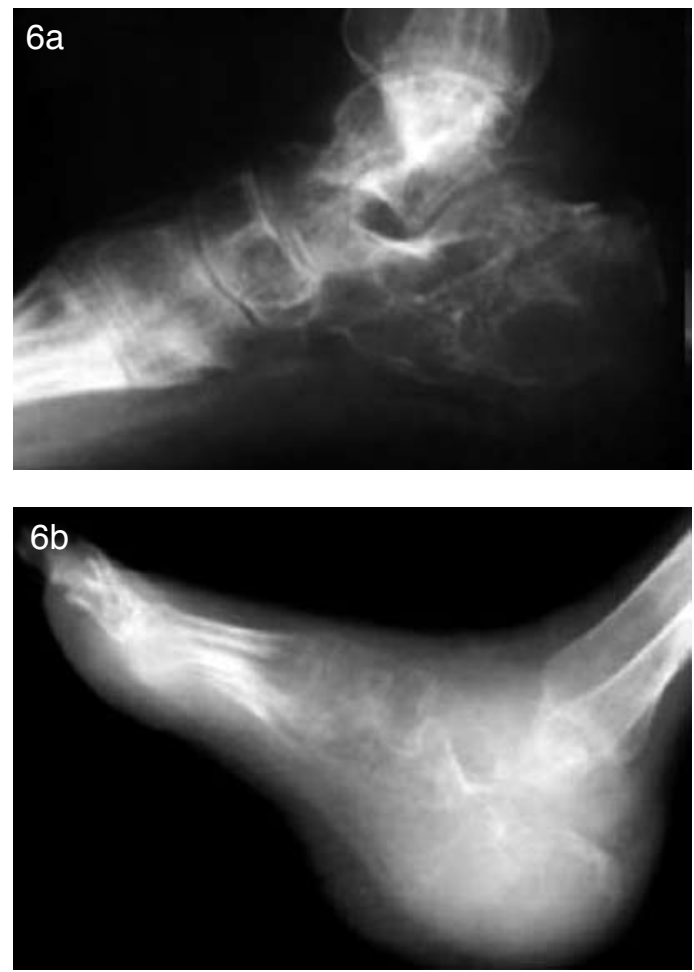

Figura 6. Varón de 30 años; deambulación dolorosa. a) La radiografía simple muestra lesiones líticas de los huesos del tarso, particularmente del calcáneo. b) La radiografía simple efectuada 6 meses después muestra la destrucción de los huesos adyacentes y la aparición de una masa de partes blandas.

Los pacientes con los HEE de la órbita y el calcáneo fueron tratados quirúrgicamente y no recidivaron. El paciente con tumor en el cuerpo vertebral lumbar murió 12 años después del diagnóstico, debido a una neumonía en la unidad de cuidados paliativos, donde ingresó a causa de cáncer de próstata.

\section{Discusión}

Las localizaciones más comunes de los HEE, de mayor a menor frecuencia, son: tejidos blandos, hígado, hueso, pulmón y piel(3,4). No hay diferencia significativa en la frecuencia según sexo y edad, si bien en hígado y en pulmón son ligeramente más frecuentes en mujeres ${ }^{(1)}$, y en hueso son más frecuentes en personas jóvenes, mientras que el hígado y tejidos blandos son más frecuentes en la mediana edad(5,6). Todos los pacientes que evaluamos eran relativamente jóvenes, con un promedio de 36 años de edad.

En términos generales, las metástasis por HEE ocurren en un $30 \%$ (por lo general metastatizan en los pulmones y los ganglios linfáticos) y la recurrencia local en un $15 \%{ }^{(1,3)}$. El $27 \%$ de nuestros pacientes tuvieron metásta-
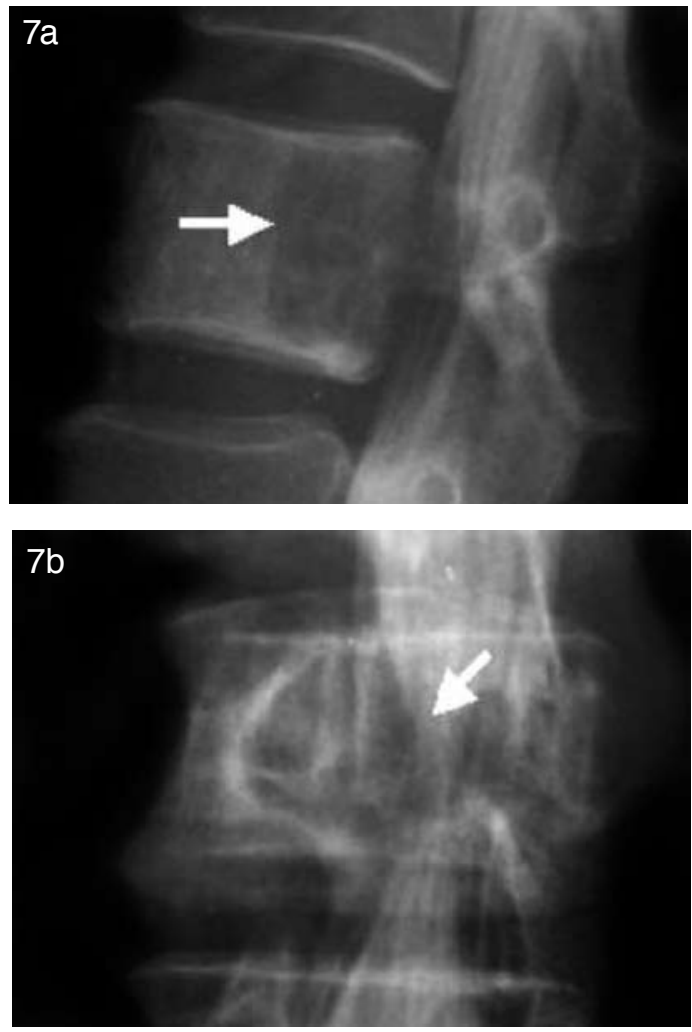

Figura 7. Varón de 50 años, con paraparesia progresiva. a) La mielografía muestra una lesión lítica geográfica en la mitad posterior del tercer cuerpo vertebral lumbar. b) La lesión producía compresión de las raíces del canal medular (flechas).

sis a distancia en algún momento de la enfermedad $(50 \%$ de los HEE de tejidos blandos y $33 \%$ de los hepáticos). El diagnóstico definitivo se basa en la histología, que es similar en los HEE independientemente de su ubicación como pudimos demostrar con nuestros pacientes. Este tumor presenta células epitelioides redondas, ovales, poligonales o fusiformes, dispuestas alrededor de los vasos sanguíneos. Estas células tienen citoplasmas eosinófilos, son positivas para marcadores CD31, CD34 y Ag-factVIII y negativas para los antígenos de membrana epitelial, marcadores neurales/musculares y citoqueratinas; las vacuolas intracitoplasmáticas son características y estas células aparecen rodeadas por estroma mixoide-fibrótico ${ }^{(3,7)}$.

En 1993 se actualizaron los criterios histológicos de diagnóstico para los $\mathrm{HEE}^{(7)}$, con el fin de diferenciar la forma más agresiva de este tumor (HEE maligno) de la forma menos agresiva de angiosarcoma epitelioide (angiosarcoma de bajo grado). Los criterios de agresividad se basan en el índice mitótico, presencia de pleomorfismo, necrosis y elongación celular ${ }^{(3)}$. El HEE está asociado a traslocación genética ${ }^{(1,3)}$ (p36.3; q25) ${ }^{(3)}$.

Como pudimos ver en nuestros pacientes, los HEE de tejidos blandos tienen un comportamiento no específico en imágenes y por lo tanto pueden ser indistinguibles de otros tumores en esta localización, 
con las técnicas de imágenes habituales. En US se presentan como masas sólidas con ecogenicidad variable $^{(8)}$; en TC sin contraste intravenoso se presentan como masas sólidas iso-hipodensas; en RM muestran una señal homogénea hipointensa en T1 (se pueden localizar componentes hiperintensos debidos a focos de hemorragia) e hiperintensa en T2. Después de la administración de contraste intravenoso, tanto en TC como en RM, los HEE se comportan de manera variable, en función de su componente de necrosis o degeneración quística: ya sea con realce periférico en aquellos con necrosis / degeneración quística, o con realce difuso y homogéneo / heterogéneo en aquellos con componente principalmente sólido, siendo este último el patrón más frecuente ${ }^{(9,10)}$. Nuestros resultados corroboran estos comportamientos, como confirmaron las muestras histológicas.

Los HEE hepáticos también poseen un comportamiento no específico en las exploraciones con US, donde aparecen como masas sólidas, por lo general hipoecoicas, debido al estroma mixoide ${ }^{(10,11)}$. En TC, las lesiones de HEE hepáticos suelen ser múltiples y presentar dos patrones ${ }^{(11,12)}$, el primero de ellos consiste en lesiones nodulares y podría corresponder a una etapa inicial que se convertiría con el tiempo en un segundo patrón más difuso, por la confluencia de las lesiones a medida que crecen. La retracción capsular puede ocurrir por la fibrosis inducida por el tumor ${ }^{(12)}$, como vimos en una de nuestras pacientes. Tras la administración de contraste intravenoso es típico el realce tardío y periférico del tumor. En RM se describe un patrón en "diana" en secuencias T2, con un núcleo central hipointenso debido a la presencia de fibrosis, necrosis por coagulación, pequeñas calcificaciones y hemorragia, con un anillo periférico hiperintenso atribuido al tejido conectivo edematoso y tejido viable tumoral ${ }^{(13,14)}$; encontramos este comportamiento en T2 en la paciente que poseía estudio de RM. Las lesiones que se comportan homogéneamente hiperintensas en T2 no tienen componente importante de fibrosis, necrosis o calcificaciones en el análisis histológico, correspondiendo principalmente a tumor viable. Tras la administración de gadolinio, se describe un realce tardío periférico ${ }^{(13,14)}$, que otorga un aspecto en diana; este comportamiento obliga a plantear diagnóstico diferencial con hemangiomas atípicos, metástasis y absceso hepático amebiano, donde resulta esencial conocer el contexto clínico y los antecedentes del paciente.

Un signo recientemente descrito, que nosotros no encontramos en ninguna de nuestras pacientes, es el signo de la "piruleta"(15), en el que una vena hepática o portal termina en el interior o en la periferia de algunas de las lesiones hepáticas. Este signo parece ser específico para esta entidad, en presencia del resto de hallazgos descritos previamente. Las lesiones hepáticas de HEE no muestran captación de agentes basados en manganeso, porque no tienen componente colangiocelular ni hepatocelular(16), como también se observó en nuestra paciente a la que se realizó RM. La administración de agentes de contraste superparamagnéticos con afinidad por el sistema retículo-endotelial permite también delimitar las áreas de parénquima hepático sano (que al captar el contraste registran pérdida de señal en secuencias que son sensibles a artefactos de susceptibilidad magnética, como las secuencias eco de gradiente-T2*) de las que están afectadas por el HEE (que permanecerían hiperintensas en T2) ${ }^{(17,18)}$.

Respecto a los HEE óseos, las radiografías simples muestran lesiones osteolíticas con componente variable esclerótico periférico (por lo general visto en lesiones de bajo grado) ${ }^{(9,19)}$. Se puede ver afectación articular y reacción perióstica, así como mineralización de la matriz y calcificaciones asociadas. En las extremidades inferiores es más frecuente encontrar una masa de partes blandas asociada, que puede ser multifocal(20); esta última característica no se encontró en ninguno de nuestros pacientes. En los casos más agresivos, estos tumores pueden causar osteolisis masiva asociada a una masa de tejidos blandos ${ }^{(19,20)}$, como se observó en el paciente con el tumor en el calcáneo. En la TC aparecen como lesiones líticas con componente esclerótico periférico variable, en función de su tiempo de evolución; después de la administración de contraste por vía intravenosa, el componente sólido del tumor suele presentar captación homogénea ${ }^{(20)}$. En nuestro paciente con el tumor en la órbita objetivamos realce homogéneo de la masa, debido al componente principalmente sólido encontrado en la muestra histológica. Por último, la RM no proporciona hallazgos adicionales, demostrando masas hipointensas en T1 e hiperintensas en T2, con realce homogéneo tras la administración intravenosa de contraste ${ }^{(9,19,20)}$. Se encontró escasa necrosis y degeneración quística en el análisis histológico de nuestro paciente con HEE en el cuerpo vertebral, por lo que su realce periférico podría explicarse debido a un suministro sanguíneo deficiente (consideramos que estudios posteriores deben valorar este punto). La presencia de estructuras vasculares serpinginosas hipointensas es poco frecuente, pero sugiere el diagnóstico ${ }^{(19,20)}$.

\section{Conclusión}

EI HEE de partes blandas aparece como una masa sólida con hallazgos no específicos. En hígado, los HEE muestran una localización periférica característica, con tendencia a confluir y realce progresivo después de la administración de contraste intravenoso.

Los HEE óseos se comportan como lesiones líticas con masas de partes blandas o edema adyacente.

Aunque los HEE son neoplasias poco frecuentes, es importante conocer sus características imaginológicas para sugerir el diagnóstico y promover el análisis histológico a fin de lograr un manejo adecuado.

\section{Bibliografía}

1. Ghekiere O, Weynand B, Pieters T, Coche E. Epithelioid haemangioendothelioma. Eur Radiol 2004; 14: 11341137.

2. Casey MC, Lim C, Hickey MC. An unusual cause of neck 
pain.Br J Radiol 2004; 77: 539-540.

3. Adler CP, Wold L. Haemangioma and related lesions. En: Fletcher CDM, Unni K, Mertens F. World Health Organization Classification of Tumours. Pathology and Genetics. Tumours of soft tissue and bone. Lyon: IARC Press; 2002. pp. 320-323.

4. Palsson B. Epitheloid hemangioendothelioma. Acta Oncológica 1999; 38: 659-661.

5. Lyburn ID, Torreggiani WC, Harris AC, Zwirewich CW, Buckley AR, Davis JE, et al. Hepatic Epithelioid Hemangioendothelioma: Sonographic, CT, and MR Imaging Appearances. AJR Am J Roentgenol 2003; 180: 13591364.

6. Kabukcuoglu F, Kabukcuoglu Y, Livaoglu A, Ozagari A, Armagan R, Kuzgun U. Epithelioid hemangioendothelioma of bone. Acta Orthop Traumatol Turc 2006; 40: 324-328.

7. Mentzel T, Ratilal B, Mafra M, Maghalaes C. Epithelioid hemangioendothelioma of skin and soft tisues:clinicopathologic and inmunohistochemical study of 30 cases. Am J Surg Pathol 1997; 21: 363-374.

8. Paltiel HJ, Burrows PE, Kozakewich HP, Zurakowski D, Mulliken JB. Soft-tissue vascular anomalies: utility of US for diagnosis. Radiology 2000; 214: 747-754.

9. Murpheil' MD, Fairbairn KJ, Parman LM, Baxter KG, Parsa $\mathrm{MB}$, Smith WS. From the Archives of the AFIP. Musculoskeletal Angiomatous Lesions: Radiologic- Pathologic Correlation. RadioGraphics 1995; 15: 893-917.

10. Radin DR, Craig JR, Colletti PM, Ralls PW, Halls JM. Hepatic Epithelioid Hemangioendothelioma. Radiology 1988; 169: 145-148.

11. Buetow PC, Buck JL, Ros PR, Goodman ZD. Malignant Vascular Tumors of the Liver: Radiologic-Pathologic
Correlation. RadioGraphics 1994; 14: 153-166.

12. Furui S, Itai $Y$, Ohtomo K, Yamauchi T, Takenaka E, lio $\mathrm{M}$, et al. Hepatic Epithelioid Hemangioendothelioma: Report of Five Cases. Radiology 1989; 171 : 63-68.

13. Farnest IV F Johnson CD. Kase 96: Hepatic Enithelioid 298.

14. Kim KA, Kim KW, Park SH, Jang SJ, Park MS, Kim PN, et al. Unusual Mesenchymal Liver Tumors in Adults: Radiologic-Pathologic Correlation. AJR Am J Roentgenol 2006; 187: 481-489.

15. Alomari Al. The lollipop sign: a new cross-sectional sign of hepatic epithelioid hemangioendothelioma. Eur J Radiol 2006; 59: 460-464.

16. Gandhi SN, Brown MA, Wong JG, Aguirre DA, Sirlin CB. MR Contrast Agents for Liver Imaging: What, When, How. Radiographics 2006; 26: 1621-1636.

17. Kehagias DT, Moulopoulos LA, Antoniou A, Psychogios V, Vourtsi A, Vlahos LJ. Hepatic epithelioid hemangioendothelioma: MR imaging findings. Hepatogastroenterology 2000; 47: 1711-1713.

18. Paolantonio P, Rengo M, Ferrari R, Vecchietti F, Vasselli F, Laghi A. Hepatic epithelioid hemangioendothelioma (HEH) at MRI using reticuloendothelial system (RES)specific contrast agent: the "bright-bright sign" rather than the "bright-dark sign". J Magn Reson Imaging 2009; 29 : 994-995.

19. Wenger DE, Wold LE. Malignant vascular lesions of bone: radiologic and pathologic features. Skeletal Radiol 2000; 29 : 619-631.

20. Larochelle O, Pe'rigny M, Lagace' R, Dion N, Gigue`re C. Best Cases from the AFIP. Epithelioid Hemangioendothelioma of Bone. RadioGraphics 2006; 26: 265-270. 